\title{
AMAR, ESCREVER, SABER DE SI: A QUESTÃO DA AUTORREFLEXIVIDADE NOS DIÁRIOS DAS FEMMES DE LETTRES ALINE DE LENS (1881-1925) E CATHERINE POZZI (1882-1934)
}

Aline Magalhães Pinto Universidade Federal de Minas Gerais

\section{RESUMO}

O tema desse artigo é a construção da autorreferência do 'eu' de um ser humano do gênero feminino, entendido como um problema teórico e histórico da modernidade. Exploraremos, de maneira comparativa-contrastativa, os diários das femmes de lettres Aline De Lens (1881-1925) e Catherine Pozzi (1882-1934) a questão da subjetividade moderna sob signo do desvio intrínseco à diferençaresistência feminina. Buscamos nos aproximar da composição dos textos de C. Pozzi e A. De Lens para elaborar as condições em que o diário, pensado como forma literária singular e não-narrativa (autorretrato), cuja validação se encontra na construção de uma 'verdade sincera', pode tornar-se autorreflexivo.

PALAVRAS-CHAVE: Discurso autorreferencial; subjetividade; reflexividade; diários.

Beatriz Sarlo, em Tempo Passado (2007), qualifica como uma 'guinada subjetiva' a disposição intelectual que traz para o primeiro plano o território da produção de si mesmo. Para Sarlo, "contemporânea do que se chamou nos anos 1970 e 1980 de guinada linguística ou muitas vezes acompanhando-a com sua sombra, impôs-se a guinada subjetiva" (2007, p. 18). Sob o impacto da "morte do homem" e do linguistic turn, o âmbito da vivência individual torna-se intelectualmente estimulante. Como bem mostra Ângela de Castro Gomes (2004), o conjunto de modalidades a que podemos chamar de produção de si no mundo constitui-se como prática cultural que permite aos pesquisadores da área de Letras e Humanidades 
abordarem os fenômenos que estão envolvidos na emergência e desdobramento histórico do individualismo moderno nas sociedades ocidentais. Evidentemente, a vida do indivíduo passa a despertar um interesse distinto daquele que mobilizou a feitura de biografias e autobiografias no século XIX. Trata-se agora de ver, no conjunto das vivências e nos registros produzidos, um estoque de possibilidades a serem analisadas e elaboradas no sentido de entender como e se é possível para nós, a constituição de uma forma autónoma e autorreflexiva de existência individual. O que requer compreender que o horizonte teórico-cultural em que se dá a conformação do discurso autorreferencial (autobiografias, diários, memórias, correspondências i.e, o conjunto de práticas que levam à 'produção de si mesmo') não se deixa reduzir à dimensão textualista - que tem como horizonte a autoficcionalização do sujeito da enunciação-, ou à dimensão historiográfica-sociológica-, que remete à problemática do testemunho e do documento. Ao invés disso, a construção da autorreferência, modo de discurso em que o eu toma a si mesmo como referente, remete à problemática filosófica da subjetivação e da intencionalidade da consciência. O que serve de esteio para uma elaboração teórica que compreenda a emergência dos estudos imbuídos no resgate de formas autobiográficas como índice do fenômeno de expansão do campo de exposição da subjetividade, num sentido próximo daquele defendido por Arfuch ao retomar o termo Espaço Autobiográfico (P. Lejeune), para designar um horizonte de inteligibilidade que visa compreender, nas escritas autorreferentes, uma hibridização das formas relacionadas a uma reconfiguração da subjetividade contemporânea (2010, p. 17).

Reconhecendo esse território como extenso e pantanoso, nossa pesquisa nele se insere, abordando-o a partir de um enclave: a construção da autorreferencia do 'eu' de um ser humano do gênero feminino, entendida como um problema teórico e histórico da modernidade. G. Simmel em seus estudos sobre a entrada da mulher no mundo público, afirmava que figura feminina, a um só tempo "real" e simbólica (assim como a cidade) aporta consigo o elemento "trágico" da paisagem moderna. O elemento trágico diz menos de um choque de forças, vontades ou ideias. Ele aponta para a circunstância em que o mundo sócio-cultural não destrói o indivíduo, mas atua constantemente restringindo-lhe a forma de permanecer. Trágico, portanto, é que a não-sintonia com esse mundo seja, em última instância, uma contradição interna ao próprio sujeito (1993 p. 136-137).

Esse ponto de vista é pertinente porque as relações históricas em que se conformam os modos de subjetividade de seres humanos do gênero 
feminino no século XX acabam por determinar que a vida de uma femme des lettres seja necessariamente uma experiência de desvio ou sinuosidade em relação ao modelo identitário previamente estabelecido para as mulheres. $\mathrm{O}$ sujeito do gênero feminino que escreve se vê marcado por uma quebra da expectativa socialmente aprovada e por uma luta pessoal contra o normatizado. Como afirma S. Felman, a constituição do sujeito feminino perpassa a hesitação de assumir uma diferença que aparece com a forma social de uma resistência (1993, p. 3-19). O que não implica a existência de uma subjetividade feminina. Buscamos investigar a questão da reflexividade da subjetividade moderna sob signo do desvio intrínseco à diferença-resistência feminina como fator histórico-social e cultural. Isso é, pensar as maneiras pelas quais seres humanos do gênero feminino se transformam em sujeitos - o que M. Foucault denomina como subjetivação, um exercício ou prática de si mesmo. Processo pelo qual se obtém a constituição de um sujeito, ou mais precisamente, em que se realiza uma das possibilidades dadas na organização de uma consciência de si (cf. FOUCAULT, 2010). Nesse processo, historicamente, os modos de viver ligados ao gênero masculino tendem a se tornar a norma: homens encarnam a humanidade, as mulheres permanecem presas em sua diferença feminina. É preciso salientar, nesse ponto, que a diferença-resistência a que nos referimos possui uma natureza circunstanciada e a condição de desvio em que os escritos autorreferênciais de C. Pozzi e A. De Lens estão embebidos não possuem um valor ontológico. A diferença-resistência, nesse caso, está intimamente relacionada à configuração histórica da alta sociedade europeia no final do século XIX e nas primeiras décadas do século XX. Catherine e Aline lidam com as rígidas exigências feitas às mulheres "normais" nesse contexto e arcam com as consequências de terem, cada uma a sua maneira, tentado romper com o pacto silencioso que as obrigava a subordinarem sua vocação intelectual às tarefas reprodutivas e sexuais. Trata-se de uma situação, não de demandas intrínsecas que permitam generalizações sobre uma misteriosa entidade chamada «feminilidade». Como aponta Toril Moi, em um pertinente artigo em que revisita, à luz de Wittengenstein, Beauvoir e Cavell, as concepções de feminino de Freud e Lacan, muitas vezes a afirmação da diferença sexual se transforma em um debate acerca de qualificativos ou faculdades que as mulheres possuem ou não. Mais especificamente, continua a autora, em termos psicanalíticos, esse debate gira em torno do conceito de castração, entendido como o desvio ou diferença que produz, como efeito, a 
feminilidade. O que está em jogo é a relação entre símbolos e corpos, e a relação entre a função simbólica e as normas sociais ou ideológicas. E, por se situar no campo do simbólico, Moi sugere, ante o inevitável caráter sexista do conceito de castração, deslocar seu sentido de falta ou lacuna para um horizonte antropológico mais profundo e abrangente: a finitude. Em suas palavras:

Analysts and theorists ought to reserve the term castration for cases where people actually do fantasize, fear, worry about losing their sexual powers. (It makes no sense to call a sexually powerful woman castrated just because the theory implies that she must be.) They should also stop speaking of castration when what they have in mind is the most general sense of lack, for this amounts to imposing a sexist and sexualizing term on all of human existence. For a philosopher of finitude, human psychic pain arises from the finitude of the human body. It is our bodies that are separate, sexed, and mortal. This is our human condition, and the task of finitude is to acknowledge it. No wonder that religions, vast philosophies, and innumerable works of art have arisen in the attempt. Psychoanalysis has always been a distinguished participant in the attempt to teach human beings to come to terms with finitude. But finitude is not the same thing as lack. Must the fact of finitude, the fact of being separate, sexed, and mortal, be figured as lack? ( Moi, 2004, p. 874)

À vista disso, investigar a questão da subjetividade moderna sob signo do desvio intrínseco à diferença-resistência feminina (fator histórico-social e cultural), faz com que nos situemos na fronteira entre a Teoria da Literatura, a História Intelectual e a Literatura Comparada para delinear as condições em que uma forma literária singular, os diários, - que se alimenta da percepção, da lembrança e da emoção para construir a 'verdade sincera' que a orienta-, pode tornar-se autorreflexiva. Entendemos autorreflexão como um caso particular da consciência intencional em que a razão - órgão humano para tudo aquilo que é ausente e, nessa medida, aquele que torna-nos aptos, pela imaginação e pelo pensamento, a ultrapassar o horizonte do atual e presente, antecipando o que ainda não está dado - se dirige a si mesma, sem se deixar naturalizar ou reduzir-se a uma identidade ou essência. O que significa dizer que, seja sob a modalidade de individualidade antiga ou sob a forma do indivíduo moderno, o sujeito produtor não deve ser tomado como a última instância para o estudo do discurso autorreferencial. Entre a escrita e o sujeito há a descontinuidade pressuposta pela vida. 
Consideramos que a forma discursiva autorreflexiva é uma possibilidade e não o destino do enunciado autorreferente. Partindo da experiência de auto-observação e autodescrição, é um discurso que escapa ao subjetivismo. Será, portanto, uma escrita que não é meramente um reflexo da posição afetiva de um sujeito ou a descrição de seu estado de espírito. Voltando-se sobre si, enuncia algo a respeito da constituição da própria subjetividade e de seu desenrolar temporal e finito. Nesse caso, um discurso em primeira pessoa está intrinsecamente ligado ao contexto da modernidade, uma vez que supõe a imersão num mundo cindido, simbolicamente intransitivo e não-harmônico, com suas contradições e paradoxos. Orienta-se por um sistema de validação e legitimidade que gira ao redor da verdade sincera e meditativa, aquela que visa o "extremo de si mesmo", se situando entre a verdade que se orienta pela adequação ao que de fato ocorreu, i.e. valor sob o qual se sustenta a especificidade do discurso historiográfico e a verdade da ficção, aquela que não é o avesso do real e sim capaz de desdobrar realidades.

Em um diário, como nos demais textos autobiográficos, impera a coincidência temporal e espacial entre o protagonista e o escritor. Essa coincidência é índice da mais básica condição de possibilidade do discurso autorreferencial: tomar a escala da vida humana como medida comum, o que viabiliza a justaposição textual entre o sujeito da enunciação e o eu que escreve. Essa justaposição, todavia, é problemática porque o estarconsigo-mesmo, num diário, radicaliza-se em um imperativo e sua aporia. É o que Maurice Blanchot nos ensina, em sua leitura dos diários de Kafka. Para o ensaísta francês, o diário traz consigo a promessa de proteção do eu que escreve contra o esquecimento, o desespero, a loucura. Para tanto, se alimenta da estranha conviç̧ão de que é possível se observar e se conhecer, isso é, finalmente, encontrar a si mesmo. Todavia, essa convicção é incessantemente traída pela inevitável descoberta, por parte do escritor de diários, de que registrar a insignificância cotidiana não conduz ao conhecimento de si como uma feliz totalidade porque leva, necessariamente, ao ver-se como migalhas de expectativas, desejos, projetos (BLANCHOT, 2005, p.270-278). Elias Canetti também aponta para a contradição inerente à expectativa de bem-estar proporcionado pela atividade diarista que deveria trazer consigo um maior domínio de si mesmo. Aquele que escreve logo percebe que a serenidade e quietude desejadas se transformam em seu mais absoluto inverso. A escrita do diário passa, então, a manter o eu que escreve num estado de alerta 
permanente. A aporética relação de estar-consigo-mesmo por meio do registro cotidiano de insignificâncias impede que o processo individual de transfiguração das experiências passadas se dê de forma linear e tranquila. Por isso, a atividade do diário assemelha-se a um ajuntar de estilhaços vazios (CANETTI, 2011, p. 59-77).

Composição fragmentária pela qual vislumbra-se uma individualidade em migalhas, o diário pode ser lido por meio do operador interpretativo autorretrato, proposto por Michel Beaujour - para quem será a ausência de narrativa aquilo que caracteriza a especificidade de um diário. Do que decorre que o desenvolvimento do texto, ainda que tenha o sujeito produtor dos textos e a cronologia como garantia de certa unidade e sentido, se dê por um procedimento de bricolagem. Ao encarar o diário como autorretrato, Beaujour desvela uma instigante perspectiva, que seguiremos: dado seu caráter fragmentário e não-narrativo, ante um diário, tal como diante de um autorretrato (pintura), o exercício da sinceridade leva de tal maneira ao encontro do vazio constitutivo da subjetividade que cada leitor passa a conhecer a si mesmo naquele vazio (BEAUJOUR, 1980, p.14-18).

\section{2}

Tendo em vista a perspectiva teórica acima exposta, exploraremos, de maneira comparativa-contrastativa, em dois registros textuais deveras singulares: os diários das femmes de lettres Aline De Lens (1881-1925) ${ }^{1}$ e Catherine Pozzi (1882-1934)². Ambas francesas, pertencentes a famílias abastadas, filhas de cirurgiões renomados e cidadãos respeitados ${ }^{3}$, formadas de acordo com as regras de boa educação reservada às mulheres de sua origem social, o que inclui o cultivo do hábito, bastante comum à época, de escrita de diários (cf. LEJEUNE, 1993).

De Lens e Pozzi desenvolveram seus respectivos diários como um espetáculo autoconcedido e um laboratório de auto-experimentações. Sobre esses exercícios, pesam não apenas o sentimento de fracasso e estranheza do indivíduo advindos do processo de instalação da sociedade burguesa capitalista, como também a experiência de incômodo e inadaptação aos modelos tradicionais de feminilidade. $\mathrm{O}$ que as empurra sinceramente em busca de entendimento de si mesmas, concomitantemente arremessaas para fora da esfera individual e privada. Seus caminhos foram bastante distintos, como veremos. Todavia, em ambos diários, encontra-se uma aguda e incessante procura pela perfeição, pelo amor, pelo sentido da vida 
e das coisas do mundo. Nessa busca, escuta-se uma inquietude existencial e religiosa que ressoa a preocupação constante com o Universal.

Aline De Lens viveu em Paris durante a infância e adolescência. Em 1902, ela se muda com a família para Versailles, onde leva uma vida confortável. Depois de frequentar a Académie Julian em Paris, De Lens é admitida, em 1904, na Ecole des Beaux-arts, onde o pintor Ferdinand Humbert havia acabado de abrir um curso em que aceitava-se a participação de mulheres. Nas idas e vindas entre Paris, onde manteve seu ateliê e Versailles, seu cotidiano é marcado por visitas aos museus e salões de arte, idas a óperas e concertos, passeios nos parques da cidade e jantares com a família e amigos. Junto às amigas de curso, De Lens alterna as lições de pintura com conversas em que dividem entre si, sobretudo, as inquietudes e incertezas de serem jovens mulheres "do mundo", isso é, que queriam se lançar ao desafio de uma carreira independente e autônoma. O registro da conversa entre amigas aponta a experiência compartilhada acerca do desafio e dos obstáculos envolvidos na aventura de ser uma mulher independente. $\mathrm{O}$ diário retrata a singularidade do impacto que frequentar esse curso causava a ela: uma mistura de entusiasmo, bonomia, insegurança, cansaço e tédio, entrecortada por crises constantes de neurastenia - que já apontavam para a enfermidade que mais tarde se revelará fatal.

Em 1908, Aline de Lens faz a primeira viagem à Espanha. Apaixona-se pela Andaluzia e por Granada, que passa a visitar regularmente. Nessas viagens, ela descobre as cores de um mundo que lhe parecia totalmente outro que o francês, faz assombrosas experiências afetivas -mas não sexuais-, com um padre espanhol que se torna um grande amigo, e desenvolve um insaciável fascínio pelo "Oriente". De Lens se encanta pelos temas, tonalidades, matizes, clima, finalmente, por algo que ela apreende como uma luminosidade alegre, louca, um pouco bizarra, mas deliciosa, que envolve a parte meridional da Espanha. Tudo a apaixona, sob o signo do pitoresco e do exotismo. A Espanha, sua herança moura e cigana, é o primeiro território de alteridade a partir do qual ela entenderá a França, os franceses, e a si mesma.

Decidida a não se casar para viver da arte, de forma independente, manteve-se solteira até os vinte e cinco anos - o que, para o período, é algo muito mal visto. Então, ela conhece num jantar, o jovem desiludido André Réveillaud, advogado e estudante de pintura, à época com vinte e um. Eles se aproximam rapidamente, e viverão um estranho, mas intenso relacionamento baseado em respeito, castidade e fidelidade. Mesmo en- 
frentando reticências de ambas famílias, eles decidem se casar. De Lens nutre por Réveillard um sentimento singular, que mistura a ternura maternal e a admiração que se tem por um amigo ou irmão. Sendo correspondida nesses termos, eles optam por um casamento branco, aquele que jamais se consuma sexualmente, mas em que há absoluta aquiescência de ambas as partes e nenhuma compensação financeira (Cf. BOLONGNE, 1997). Num pacto de cumplicidade ímpar, decidem compartilhar a vida juntos. Em 1911, eles partem para a França Colonial, onde o rapaz havia conseguido um posto como funcionário público. Os anos entre 1911 e 1913, vividos na Tunísia, serão reconhecidos por De Lens como uma tranquila felicidade e integração à vida comum e ao ambiente "mourisco" que tanto adorava. Esse ambiente serve de inspiração para alguns quadros e para uma série de pequenas narrativas, publicadas pela Revue de Paris e depois, em 1919, pela editora Calmann-Lévy com o título Le Harem entr'ouvert.

Esse estado de coisas não permanece inalterado por muito tempo. Ao final de 1913, em meio às convocações para a integração ao exército francês, seu marido é realocado em Rabat, no Marrocos, dando início ao que ela considera um verdadeiro pesadelo: viver em uma paisagem em que não havia mais do que imundice e feiura, além de uma grave epidemia de tifo. Quando Réveillaud é nomeado como controlador civil, eles passam a viver em Meknès. Entre 1915 e 1920, De Lens nos revela uma vida cotidiana atribulada, seja pela ressonância da Primeira Guerra, que afeta intimamente o mundo colonial francês, seja pelos muitos atritos entre o modo de vida europeu e o local, que procura descrever minuciosamente como forma de compreendê-lo. O diário de Aline De Lens se torna um documento importante para o entendimento da questão colonial e da vida dos funcionários do Estado Francês em serviço nos protetorados $^{4}$.

Compartilhando do convívio dos nobres árabes, pelos quais nutre certa admiração, a ela é permitido adentrar o mundo feminino muçulmano - que lhe parece sempre medonho, bizarro. O registro dessas impressões é bastante sombrio, em grande parte devido ao fato de que todas as moças que serviam como domésticas em sua casa (meninas pobres vendidas como escravas pelos próprios pais), ocupando o dúbio lugar entre filha adotiva e empregada, quando atingem a idade de matrimônio, casam-se e vão embora. $\mathrm{O}$ que ela interpreta como uma profunda ingratidão. Além disso, a dedicação ao trabalho como pintora torna-se, pouco a pouco, cada vez mais difícil, em decorrência de um câncer cerebral, doença cujo diag- 
nóstico aparece apenas em 1920, mas da qual ela já sentia os sintomas desde 1905 (dores de cabeça e fatigas inexplicáveis, crises de "nervos" e angústia e ainda, algumas vezes, febre). Mesmo sem o diagnóstico preciso, De Lens foi operada pela primeira vez em 1906, cirurgia que parece ter lhe trazido algum conforto. Uma segunda cirurgia será realizada em 1921. Nessa ocasião, foi tomada por intensas crises de ansiedade e aflição - o que a leva a buscar auxílio na psicanálise (ainda em vias de consolidação como terapêutica). Conduzidas por um médico francês exilado em Casablanca desde a Guerra, as sessões visavam conter os ataques de paranoia e neurastenia que passam a ser cada vez mais frequentes.

Em 1921, Réveillaud deixa o serviço na administração colonial e passa a trabalhar em Fez, como advogado autônomo para a nobreza árabe. Mesmo atormentada pela doença, De Lens o acompanha. O registro de seus últimos anos é constituído pela alternância entre tentativas de rememoração de lembranças perdidas da infância, especialmente aquelas da relação com o pai; a descrição tortuosa do medo de morrer e a afirmação constante do amor eterno e puro que a une ao marido - malgré o fato (desconhecido por ela, ao que parece) de que Réveillaud manteve em Fez,uma relação amorosa com Suzanne Drouet (uma antiga colega de Aline na Ecole des Beaux-arts, que recebe uma bolsa de estudos para viver em Marrocos). Essa relação se torna oficial poucos meses após da morte de Aline, em fevereiro de $1925^{5}$. Todavia, o casamento dura muito pouco, pois Réveillaud morre em um acidente de carro em março de 1926.

C. Pozzi tem uma trajetória diferente. Desde cedo, alimentou ambições intelectuais relacionadas às ciências (estudos de química, física e biologia), embora o pouco reconhecimento que hoje receba seja devido a seis poemas que, acolhidos por Jean Paulhan, são publicados postumamente na Nouvelle Revue Française e posteriormente inclusos na antologia decisiva organizada por André Gide em 1949. Seus poemas são considerados representantes sofisticados de uma poesia neoclássica, ou pelo menos não vanguardista. Um desses poemas, “Ave", receberá uma bela interpretação de Michel De Certeau, que explora seus elementos místicos (1982, p. 407-411).

Relutante às perspectivas reservadas para as mulheres de seu meio social, Pozzi tentou sem êxito, no final da primeira década do século XX, estabelecer-se na Inglaterra. Retornando a Paris em 1909, pressionada por um ambiente onde uma mulher solteira aos 25 anos não tem acesso à vida social, casa-se com o autor de teatro Edouard Bourdet e tem um 
filho, Claude. Embora ela jamais se divorcie oficialmente, a união dura muito pouco. Em 1920, Catherine Pozzi conhece e se apaixona por Paul Valéry (1871-1945) de quem desejará ser inspiradora, amante e cúmplice. Pozzi e Valéry embarcam numa aventura amorosa projetada sob um sentido místico - que ganha corpo, para os leitores de hoje, no que sobrou da correspondência entre ambos (reunida e publicada pela Gallimard em La flamme et la cendre, 2006) -, na medida em que compreendem o sentimento que sentem um pelo outro como o contato entre dois espíritos que se identificam e se justapõem de maneira que o conjunto formado provoca uma fusão entre ser e conhecer. Essa concepção gera efeitos devastadores sobre Pozzi, que sofre ao ver o amor se transformar numa constante e triste dor maníaca. A relação, intensa e entrecortada, será rompida definitivamente em 1929. Momento em que o sofrimento afetivo soma-se à sensação de fracasso intelectual, à solidão e às condições físicas cada vez mais degradantes devido ao avanço da tuberculose. Pozzi é diagnosticada com tuberculose em 1912, mas apenas em 1921 os sintomas se farão notar de forma sistemática e persistente. $\mathrm{O}$ aparecimento do primeiro abcesso tuberculoso em seu corpo, em 1924, emerge como eixo de inflexão de sua vida e índice físico de sua derrocada. Os médicos não o associam imediatamente à tuberculose e, durante meses, as suspeitas variaram entre tétano, câncer e sífilis. Por fim, optam por extrair o abcesso. Pozzi será submetida a três procedimentos cirúrgicos delicados e, em seguida, a um tratamento experimental, em que um composto feito a partir do material retirado nas cirurgias é injetado em seu sangue, na tentativa de obrigar o corpo a produzir anticorpos. $\mathrm{O}$ resultado é catastrófico e acelera a evolução da tuberculose. A partir de então, Pozzi afirma que sua vida toma a forma do sofrimento (POZZI, 2005, p. 333-334).

A consciência da progressiva deterioração de seu corpo, decorrente da tuberculose, o fracasso de seus relacionamentos afetivos, em especial, a relação amorosa malfadada com Paul Valèry e a vocação intelectual frustrada são emoções que aparecem amalgamadas. Elas conduzem e conferem o tom quase sempre sombrio das páginas do diário. Ao fim da vida, C. Pozzi enfrenta a tristeza de não ter tido, durante a vida, coragem e a força de cumprir publicamente seu papel como intelectual. Nos meses que antecedem sua morte, o diário se torna palco dos apelos desesperados ao filho para que ele publique o ensaio filosófico que ela passa a vida toda tentando escrever e que ela nunca termina, a despeito da insistência 
de Jean Paulhan em publicá-lo. A autorreflexão nesse momento ganha os contornos de um juízo implacável: a necessidade de pureza e rigor teriam sido equivalentes, para ela, ao orgulho. Sem ter sido capaz de distinguir o orgulho da exigência de extremo rigor, o resultado prático foi a infecundidade: ela não termina a composição do livro e de sua teoria. O livro inacabado é um símbolo dúbio: com a aproximação da morte, ele traduz um esgotamento e, ao mesmo tempo, é testemunha de uma coragem vaidosa que renuncia à escrita (cf.BOUTANG, 1991, p. 55-60).

\section{3}

Buscamos nos aproximar da composição dos textos de C. Pozzi e A. De Lens reiterando nossa questão principal: entender em que condições o diário, pensado como forma literária singular e não-narrativa (autorretrato), cuja validação se encontra na construção de uma 'verdade sincera', pode tornar-se autorreflexivo. Começamos esse exame destacando uma passagem de cada diário ${ }^{6}$.

Paris, sábado à noite, 22 de novembro de 1913.

Outra manhã na Biblioteca Nacional, como eu voltava pra deixar uma pilha de [livros sobre] sabedoria oriental e as Memórias da Sociedade Real de Ciências, para o premiado rabugento cujo humor resistiu ao esgotamento eterno das coisas e que ao término de um ano e meio, eu vejo novamente com a ruga hostil dos seus lábios nos quais provavelmente nenhuma célula tocou - ó doçura de Biblioteca onde os bananas de cabaret não tiveram nem o tempo de amadurecer -, eu cruzo com Daniel Halévy, com casaco de pintor, meio operário usando veludo, pensativo e gentil: dizer-lhe olá, pensar sobre o que nós fazíamos ele prepara um estudo sobre Maurras e relê seus artigos sobre o Caso [Dreyfus] - eu, tão mais intelectual! - e continuar o caminho. Eu the pedi para me emprestar seu livreto Apologia ao nosso Passado Desaparecido, sem perceber que isso era indiscreto ou que ele esqueceria inclusive. E eu recebo o livreto, que em cem anos ainda será lido pois tem uma sinceridade inteligente e coragem moral sobre a história da mais lúgubre entre as aventuras políticas.

Eu sou de uma inquietude incompreensível, not account for. Uma sede: uma desagradável sede persiste; há três semanas eu crio uma história - imaginando doces episódios, os olhos fechados na noite negra, esta hora que é entre hoje e amanhã -, história medíocre, e completamente inocente desses pensamentos culpados e devassos. Eu não sei 
qual apetite do coração estranho me mantém e me persegue. Ele ou um outro, qualquer um... Infelizmente! O que quer este sexo degradante e a quais ares aspiram estes nervos, violões românticos?

Honesta, eu tentei trabalhar. Então, Bilblioteca Nacional onde Daniel Halévy, tão livre que é, me invocou a sonhar sem que eu o queira. Mas eu não tenho a força física: duas manhãs de textos hindus e eu parecia ter sido enterrada viva.

Eu me agarro a Fritz Kiener. Esse aí é um presente do Acaso, do caro Acaso. Ele é infinitamente apegado a mim e, apesar da sua feiúra, eu sonhei - de novo! - que eu me jogava nos seus braços, aos prantos. Isso eu poderia bem ter feito. Ó Fritz, meu amigo Fritz, compreensivo, irônico, germânico altruísta, como eu estaria bem em seu coração, se você soubesse! Em um coração, qualquer coração... Você embarcaria nessa viagem se um demônio lhe mostrasse estas linhas?

Idiota. Fêmea. Útero e mediocridade (POZZI, 2005: p.57-58)

Versalhes, 8 de maio de 1905.

Faz calor, eu sou preguiçosa e desperdiço meu dia. Isso acontece muito frequentemente. Eu me entedio. Meu desenho não funciona, já tem um tempo que nada vai bem. Quanto ao resto eu não preciso me surpreender, é sempre assim pra mim desde o mês de abril; uma espécie de cansaço crônico produzido pelo trabalho do ano. Eu sei bem disso, entretanto eu tenho desalentos a lamentar diante dos meus desenhos. Eu quero me forçar, eu me faço ainda mais mal, como se fosse possível, e eu percebo muito bem que isso não serve de nada, e até isso é ruim. Então uma carta, ler um pedaço de jornal, se arrastar de um cômodo a outro? Mas isso é tempo perdido, tempo que não se achará mais e depois isso me entedia terrivelmente.

Na semana passada nós fomos à Ópera, Marguerite e eu, com os Dieterle, ver Tristão e Isolda. É maravilhoso, sobretudo o último ato, o da morte de Isolda e de Tristão. A gente pensa no romance de Wagner e da senhora Wesendonck que ele quis sintetizar na sua ópera. A verdade foi ainda mais triste. Eles não morreram, mas ele esqueceu. É Van Dyck que encarnava o papel de Tristão. Ele interpretou muito bem e sua voz, mesmo se fraquejava em alguns momentos nessa música tão dura para os cantores, é ainda tão bela. Mas o seu físico é feio demais. E pode-se 
representar um Tristão pequeno e obeso com uma grande cabeça meio rechonchuda cercada de barba ruiva? Senhorita Grandjean estava muito boa como Isolda, mas não me empolgou.

Domingo eu voltei ao Salão [dos artistas] com Marguerite. Eu revi as salas já visitadas, os maravilhosos quadros de Sorolla J. Bastida, de um aspecto tão vivo, com uma amplitude de toques, uma intensidade de luz tão surpreendente! A Greve de Veneza por senhorita Rondenay teve um sucesso muito merecido, é muito humano, muito sentido e tem, sobretudo no primeiro plano, miseráveis verdadeiramente trágicos, mas o conjunto do quadro me parece um pouco grande, um pouco vazio pela composição e tem à esquerda uma grande muralha nua que não é muito interessante. Ela deve estar muito feliz em poder produzir uma obra como essa. Não tem nem 6 meses que ela entrou na Escola, eu acho. Gosto muito do Les Morphinomanes de Matignon onde, sob a luz fraca, se hipnotizam e se deitam em divãs, mulheres de uma beleza estranha e frágil. É um colorido encantador e bizarro como o assunto e faz pensar logo no poema de Baudelaire.

De Chabas, tem uma deliciosa pequena ondina de olhos e cabelos pálidos que se banha num lago sob um raio do luar. Esse corpo de criança com formas franzinas e puras e charmosas e o conjunto é de uma harmonia muito elegante. E depois tem também Les jeunes filles de l'île de Marken, do bom Bail, de um sentimento muito belo. A carga fogosa dos couraceiros de Detaille, À caça da glória e depois... e depois a gente está tão cansado que só pensa em ir embora. ( DE LENS, A. 2007: 47:49)

O primeiro ponto que se destaca na leitura dos dois registros é a mobilização dos elementos básicos de referência espaço-temporais: data e cidade. A esses marcadores somam-se a indicação de horários e dados meteorológicos, pessoas e conversas, o apontamento de lugares e de seu uso social, leituras, pesquisas e atividades culturais. Esses elementos circunscrevem o cenário em que o eu que desempenha a ação coincide com o eu que escreve. Delimitar não é meramente descrever um ambiente. Ou melhor, por meio da descrição desses planos da cena, constitui-se um sistema de referências mobilizado para situar o sujeito da ação, para posicioná-lo. Dentro do discurso, os elementos desse sistema, ligados à paisagem visual, ao meio social e ao tempo-calendário, são resultado da busca por pontos de orientação para escrever sobre si.

Esse sistema de referências não reproduz fielmente uma realidade. 
Pelo contrário, ele é uma composição discursiva e, portanto, produto de um recorte e composição de uma moldura - de uma seleção e organização que, sendo criação das autoras, ao mesmo tempo, serve de fiança ao eu que se deixa retratar. $\mathrm{O}$ caráter não fortuito desse recorte está claro nas passagens que destacamos: Catherine Pozzi, suas manhãs de sábado dedicadas ao trabalho intelectual e aos flertes, na BNF, estão claramente em sintonia com a livre-pensadora que aspira ser; Aline De Lens, apreciadora crítica do mundo das artes, frequentadora da L'Ópera de Paris e dos salões de arte moderna, realiza atividades que preconizam a pintora que ela pretende se tornar. Aquilo que, da totalidade do cotidiano, elas selecionam para aparecer como cenário no diário está em afinidade com que o que elas desejam ser. Essa moldura constitui uma projeção do que eu deseja ser, sem que constitua um gesto de ficcionalização de si mesmo, pois a descrição seletiva não libera a linguagem de sua função pragmática.

$\mathrm{O}$ procedimento organizacional autodescritivo, que permite ao eu se movimentar e se posicionar dentro de um quadro mais ou menos estável de referências externas, prende o texto ao âmbito pragmático. A apresentação ou emergência, nessas condições, dessa moldura descritiva, cumpre a função de fundo ou base que torna possível a relação analógica e verossímil entre o eu que escreve e o e $u$ representado pela escrita no enunciado autorreferente. Isso é, a produção de informações sobre si mesmo proporciona uma comunicação de tipo analógico e sincero o "eu mesmo". Sendo basilar, essa comunicação analógica, em que se justapõem autodescrição e autoobservação não esgota, contudo, o modo discursivo autorreferencial. Tampouco oferece as condições de possibilidade para que sua validação (a verdade sincera) se torne autorreflexiva. A condicionalidade desse tipo de verdade está relacionada à capacidade da escrita de si ressoar o vazio constitutivo da subjetividade moderna ${ }^{7}$. A verdade sincera nos faz ouvir o ruído do eu que escreve ter sido obrigado a estar consciente da fatalidade da vida. Essa ressonância acontece quando a direção hegemônica do conjunto de enunciados se interrompe, gerando, num estalo (instante-instância), uma transposição transgressora da analogia. Essa transposição cria um curto-circuito entre ironia e sinceridade, o que terá inevitavelmente uma estrutura metafórica.

Entendemos o diário como um texto composto por essas duas camadas ou níveis (a descritiva-observadora e a reflexiva) que respondem a uma dupla demanda: a necessidade do eu que escreve se reconhecer, isso é, de configurar um sistema de informações e referências sobre si mesmo, 
realizando-se discursivamente, soma-se à necessidade de criar uma esfera de reflexão sobre essa realização, logo, uma autorreflexão. A sinceridade ata as pontas dessa dupla necessidade. A forma sincera, autorrefletida, aparece como uma verdade que queima.

Essa hipótese interpretativa toma o diário como uma conjugação da construção de um sistema de autorreferência, isso é, um sistema analógico em que o lugar da enunciação tende a se sobrepor à situação de referência, e uma transposição transgressora dessa analogia, uma autorreflexão que precisa ser metafórica. Como poderemos ver melhor a partir da análise das duas passagens ${ }^{8}$ que transcrevo a seguir:

Fez, 29 de maio de 1920

Antigamente, eu acreditei ser independente e forte; tive vontade de fazer minha vida sozinha, por mim mesma. Os anos que se passaram me ensinaram minha fraqueza e que eu precisava tanto dele. Uma necessidade tão intensa que ela se tornou uma tortura.

É inútil escrever meus pensamentos hoje. Eles se apressam na minha cabeça contra a minha vontade e me atormentam. Retorno a esse estado nervoso que tanto me faz sofrer, há tanto tempo, do qual eu acreditei que jamais sairia e que se acalmou para a maior felicidade da minha existência. Essa felicidade existe ainda, intacta, segura de si mesma. É nela em que eu me agarro, a que eu peço socorro. Será que conseguirei? Será ela mais forte que o desequilíbrio do meu cérebro? Não pensar mais, não raciocinar mais, viver bestamente, sem preocupação, como se a gente devesse sempre viver, ser uma simples bruta: esse refinamento intelectual que a civilização coloca em nós e que o homem celebra com orgulho é o próprio instrumento do sofrimento. (DE LENS, 2007, p. 284)

10 de junho, 1931, em Vence.

Todo mês de maio é muito miserável. Doutor Labonnette: "Você tem crises de epilepsia do nervo pneumogástrico... Não é exatamente asma, é uma crise nervosa-respiratória".

Perto do Pentecostes, o tempo se torna enfim agradável e a febre diminuiu.

No dia 29 de maio me trouxeram aqui. Fui trazida carregada. Aqui, eu achava que ia me curar imediatamente, como em 1925, depois do mar- 
tírio dos dezoito meses infernais. Mas naquela época, eu ainda estava inteira, eu não tinha abandonado a mim mesma. E então, eu tomava morfina todos os dias, o que permitia em todo caso que a máquina enferma tivesse dez horas de repouso. Agora, tem um trapo, um véu de alma flutuando ao meu redor, como um trapo. E, agora, eu não tenho mais morfina. Sim, hoje tomei, só tinha um pouco. De qualquer modo, é graças a esse pouco que consigo escrever.

Ontem, eu encarei a morte. Aí está uma palavra que esses cadernos conhecem. Sim, mas eles não acreditam mais nisso.

O Herói-é-um-simulador-ou-um-imbecil veio ainda à beira da minha janela, oito dias antes de minha partida (no sábado, véspera do domingo de Pentecostes). Quem o acreditaria? Ah, nem mesmo os ingênuos da Academia. Partamos, não importa. Aquela que parte não deixa nada, apenas todo o seu passado. Suspirar, suspirar, recusar o passado.

58 respirações por minuto, doutor... (POZZI, 2005, p. 617)

Os excertos de ambos diários giram ao redor de dois núcleos principais: a doença e o amor. A. De Lens os atrela à perda da força interior: de um lado, a doença, que reúne a inadaptação aos critérios de uma sociedade racionalizada conforme um modelo de civilização e o desconforto por se descobrir nas franjas dessa civilização, à dor física e à confusão mental. Do outro lado, o amor, encarnado na relação de companheirismo que ela mantém com seu marido-amigo, como única fonte de algum conforto e esperança de felicidade. C. Pozzi também escreve ao redor desses dois núcleos, mas de uma forma distinta. No trecho que destacamos, ela evoca uma diferença entre a estadia em Vence em 1925 e a de 1933. Em 1925, ela ainda estava inteira, não havia abandonado a si mesma. Esse abandono diz respeito ao tipo de relacionamento que ela estabelece com P. Valéry. No verão de 1925, ela havia passado com ele, nessa casa (que é de sua família), algumas semanas bastante felizes - e isso era, de fato, mais significativo do que o estágio objetivo de sua doença, que era igualmente péssimo. Em 1933, todavia, Valéry havia se transformado no "Herói simulador ou imbecil" e ela estava destinada a esquecer e a ser esquecida. O término da relação com Valéry, com quem se identificava intelectual e espiritualmente, converteu-se em um desamparo íntimo.

Começaremos a destrinchar a análise pelo primeiro núcleo que apontamos: a doença. Sontag, em Ilness as a metaphor [1978], mostra como na trajetória da história da cultura ocidental, as formas como a fic- 
ção ocidental e os discursos médicos, psiquiátricos e militares, recorreram às moléstias para engendrar representações atribuídas a um destino cruel e trágico ou recebidas como punição. Inclusive, e curiosamente, tratamos aqui de "personagens" que sofrem das duas doenças que são o foco do ensaio de Sontag, justamente por serem aquelas mais sobrecarregadas, segundo a autora, pelas armadilhas da metáfora na sociedade moderna: o câncer (Aline de Lens) e a tuberculose (Catherine Pozzi). Como afirma Sontag, todo um imaginário popular e literário liga essas duas doenças, de maneira inexorável ou quase, a um diagnóstico fatal (SONTAG, 1978, p. 7-11). Não obstante, num estudo como o que propomos (e que se apresenta em consonância com a proposta geral de Sontag) ${ }^{9}$, a doença não deve ser considerada uma "ilustração" da morte senão como uma espécie de plataforma ou dispositivo que torna a "indesejada das gentes" metaforicamente pensável e representável.

Esse tratamento teórico requer problematizar o valor de antropogênese atribuído à morte, e para tanto, é importante retornar - por um instante - à base do argumento desenvolvido por Freud, ao texto Considerações atuais sobre a Guerra e a morte, de 1915 - único dentre os escritos freudianos em que a morte encontra lugar como experiência de finitude e não somente como redução ao zero das tensões vitais. Enquanto a primeira parte do texto se destina a lidar com o aturdimento gerado pela Primeira Guerra Mundial; a segunda parte, Nossa atitude perante a morte, lança-se sobre a questão da relação entre morte e sentido. Seguindo a argumentação freudiana pode-se derivar que a relação entre o homem e sua morte é marcada pela irrepresentabilidade da última. Para Freud "no inconsciente cada um de nós está convencido de sua imortalidade". E a partir daí, ele sustentará, ao longo de sua obra, a ideia de que nada no inconsciente é capaz de dar conteúdo ao próprio aniquilamento. Essa incapacidade de engendrar um conteúdo à própria morte é um traço que constitui um elo forte e permanente entre o homem moderno e os homens de todos os tempos. A irrepresentabilidade da própria morte é uma instrução elementar e nuclear para o tipo de análise que propomos. Com efeito, na mesma direção, Paul Ricoeur, em seu último e inacabado livro, Vivant jusqu'à la mort, reflete a respeito de uma batalha, um movimento transcendental da consciência intencional, travada por aquele que sabe, com uma precisão variável, que vai morrer -, contra a força imaginária e sem-imagem da morte (2007, p. 45-47). Esse combate, que se dá aos olhos de um espectador em uma escrita, toca a medula da experiência 
antropológica da finitude, na medida em que envia ao problema da representação do irrepresentável.

Eis o que temos no caso dos registros textuais dos diários de C. Pozzi e A. De Lens. O que eles produzem como efeito, é uma imagem quase inimaginável: um retrato que confere forma ao exercício de ver a si mesma morrer. A relação com a morte, a forma como ela afeta a vida, seu impacto sobre a duração do tempo em que se vive, sua irrupção no tempo, (ou erupção para fora do tempo?) não é apreendida como uma experiência que dá ao conhecer. Não se trata de uma imperfeição ou deficiência do conhecimento, mas do fato de que o que se busca, no caso de um discurso autorreferencial, se subtrai a toda possibilidade de experimentá-lo, representá-lo e conhecê-lo. É antes uma falta de experiência da morte, como uma modalidade temporal que exige mais que qualquer coisa escrever: flagrar o instante-instância em que se dá a transposição transgressora desempenhada pela metáfora. Chamamos a atenção, momentos atrás, para o fato de que essa transposição transgressora configura um curto-circuito entre ironia e sinceridade. A passagem gera uma faísca que permite 'representar' o irrepresentável: o desenrolar temporal, i.e finito da consciência subjetiva que se deixa revelar na distância entre o eu que escreve e o eu que vai morrer. Não se reduzindo simplesmente a uma antecipação, é "angústia" à qual a resposta mistura escrita, imaginação e pensamento.

No trecho destacado, A. De Lens afirma: "É inútil escrever meus pensamentos hoje. Eles se apressam na minha cabeça contra a minha vontade e me atormentam". Toda a dificuldade do problema desse tipo de escrita se apresenta: insuficiente, infrutífera e imprestável. Escrever sobre si ante o sofrimento projetado em direção a um vazio, estilhaça o eu ao invés de recompô-lo. Entretanto, e paradoxalmente, para piorar as coisas, a escrita se faz imprescindível, pois permite ao eu tomar distância e ver-se intimamente atado às fontes do desequilíbrio e dor. C. Pozzi nos diz: "Ontem, eu encarei a morte. Aí está uma palavra que esses cadernos conhecem”. Ver a morte, uma expressão recorrente em seu diário, refere-se a uma experiência ou a um desejo que deveria se condensar como palavra? Em seguida, ela afirma: "mas eles [os cadernos] não acreditam mais nisso". Os cadernos não acreditam (e aqui mais um indício da forma como os diários funcionam como uma instância meditativa quase autônoma), não podem: há uma obstrução que interrompe o fitar a morte. Pozzi, assim como De Lens, não pode acessar discursivamente ao ponto em que tudo se perde (a própria morte), senão por meio do estabelecimento de um 
drible que é também uma reinvindicação, uma demanda, um apelo. Mas elas não apelam pela vida, pela sobrevivência. Então, pelo quê? O amor aparece como como zona de idealidade que funciona como instância para a autorreflexão de uma vida que se esvazia e que encontrará inevitavelmente seu fim. $\mathrm{O}$ amor não preenche o vazio, ele o revela. Tematizando o amor que deixa de dizer de uma experiência psicológica e individual para falar o que não se pode dizer, a escrita autorreferencial salta do plano descritivo para o reflexivo-metafórico. O eu que escreve está de partida, mas ama. O leitor sente a sinceridade do texto. Ao colocar o amor no lugar da morte, a escrita do diário produz o efeito de quebrar a perversa banalidade do infortúnio de outrem. Ou, se quisermos, produz compaixão - entendida numa chave de leitura com respaldo aristotélico, como um atributo humano que expõe um horizonte de perigo que se estende para fora daquele que a sente (cf. HALLIWELL, 2002, p. 207-233).

Nos diários de Pozzi e De Lens, a relação entre doença e amor é metafórica no sentido de que essa relação coloca propriamente em cena a passagem, o transporte no qual de uma ponta a outra, uma vida se mostra, ela mesma, mas como nada, um puro vazio de sentido. $\mathrm{O}$ transporte metafórico é aí essencialmente vazio - nada mais que tempo, dilaceramento e extirpação do próprio tempo, enquanto duração da vida. Na tentativa de metamorfosear um nível narcísico de afecção e sofrimento, resultante de uma inadequação generalizada da qual a doença se torna o índice mais agudo, elas recorrem a uma ideia de 'amor" na qual a intensidade do consolo depende da agonia. Como uma espécie de camada subterrânea a cada enunciado - a metáfora se constitui como um dentro, uma interioridade, em íntima afinidade ao radical vazio e fragmentação da subjetividade moderna. 


\title{
LOVING, WRITING, SELF-AWARENESS: THE QUES- TION OF SELF-REFLECTION IN THE DIARIES OF THE FEMMES DE LETTRES ALINE DE LENS AND CATHERINE POZZI .
}

\begin{abstract}
The theme of this paper is the shaping of the feminine self through self-reference, understood as a theoretical and historical problem of modernity. We will explore the question of modern subjectivity as a sign of intrinsic deviation from feminine difference-resistance in the comparative-contrastive journals of the femmes de lettres Aline De Lens (1881-1925) and Catherine Pozzi (1882-1934). We examine, in the composition of C. Pozzi's and A. De Lens's texts, the conditions in which the diary, thought of as a singular and nonnarrative literary form (self-portrait), whose validation is found in the construction of a sincere truth, can become self-reflective. KEY-WORDS: Self-referential speech; subjectivity; Reflexivity; Diary
\end{abstract}

NOTAS

${ }^{1}$ A publicação do diário de Lens, em 2007, traz um prefácio de Sapho e foi editada por Martine Lévy e Antoinette Weil a partir de dois manuscritos que não conformam a integridade do que foi por ela escrito já que, em uma viagem à Europa, ela perdeu parte de seu diário. O primeiro dos originais que compõe a versão impressa com que trabalhamos, termina no final de agosto de 1921 e, confiada por André Réveillaud aos irmãos Tharaud, hoje se encontra na Bibliothèque Nacionale de France (BNF). O segundo caderno manuscrito, que contempla os anos entre 1921-1924, permanece em posse da família De Lens (cf. Amster, 2009).

${ }^{2}$ C. Pozzi inicia seu diário aos 13 anos, em 1893, e o manterá, salvo um pequeno 
período de interrupção, até o fím da vida. Seu filho, Claude Bourdet, fica responsável por cumprir o desejo da mãe e deposita os manuscritos, que contém desenhos e anotações dela e de Valéry, na BNF. Ao todo são cerca de 40 cadernos, publicados como Journal (1913-1934) e Journal de Jeunesse (1893-1906). A primeira edição dos diários de C. Pozzi data de 1997. Utilizamos aqui a segunda edição, ampliada e revista, (Phébus, 2005).

${ }^{3}$ Émile Delens (1840-1917) foi cirurgião, membro da Légion d'honneur e professor da Faculté de Paris, realizando estudos cirúrgicos importantes especialmente sobre a região do sacro e cóccix. Samuel Pozzi (1846-1918) foi senador, era um republicano fervoroso e humanista e circulava pelo ambiente intelectual e literário parisiense. Lançou um dos primeiros livros sobre cirurgia em mulheres, no campo recém-batizado como ginecologia. Contribuiu igualmente para os estudos sobre antissepsia e anestesia e tornou-se, em 1888, presidente da Sociedade Francesa de Antropologia. Descrito como extremamente bonito e charmoso, era íntimo de muitos expoentes da época - Marcel Proust, Georges Clemenceau, Robert de Montesquiou, Leconte de Lisle e Sarah Bernhardt, com quem viveu uma amizade apaixonada. Assassinado por um antigo paciente, seu cortejo fúnebre reuniu, segundo o jornal Le Figaro de 18 de junho de 1918, os mais marcantes personagens da ciência e da política. Para mais sobre Samuel Pozzi cf. Costa, C. da (2010).

${ }^{4} \mathrm{O}$ diário de $\mathrm{A}$. De Lens está profundamente ligado à situação colonial tanto pelas responsabilidades profissionais do marido quanto em razão da ambígua relação que manteve pelo Magrebe e pela cultura islâmica. Como mostra o historiador C. Ghiati, algumas escritoras das primeiras décadas do século XX, como De Lens, Marie Bugéja e Henriette Célarié, escreveram narrativas que tiveram enorme sucesso na França e por isso, contribuíram para consolidar uma imagem da França colonial entre os franceses. (Ghiati, 2011)

${ }^{5}$ Cf. Suzanne Réveillaud Kriz, L'Odyssée d'un peintre : Drouet Réveillaud, Paris, Fischbacher, 1973.

${ }^{6}$ Tradução de minha responsabilidade. Originais em anexo.

${ }^{7}$ Seguimos, para esse ponto, a posição de Hans Blumenberg, sintetizada de forma excelente no comentário de Padre Vaz: "Entre as mais notáveis críticas de justificação da modernidade do ponto de vista de uma reflexão sobre a cultura merece especial atenção a do filósofo e historiador das idéias Hans Blumenberg (1920-1996). Autor de uma obra multiforme que se estende a toda história da cultura ocidental e apoiada numa vastíssima erudição, Blumenberg reúne todos os fios da sua intensa meditação justamente numa teoria da modernidade pensada e formulada como demonstração da novidade e legitimidade da cultura moderna e recusa de todo paradigma hermenêutico que faça uso do conceito de "seculari- 
zação" ou de explicações que recorram a permanência de arquétipos teológicos no universo conceitual da modernidade. (...) A obra em que expõe ex professo sua leitura da modernidade denomina-se justamente $A$ legitimidade dos tempos modernos na qual é posto em questão o paradigma da "secularização". Não é pela transformação e um conteúdo teológico em conteúdo mundano que a modernidade se define. (...) A modernidade se caracteriza pela aparição histórica do vazio de sentido. Esse vazio solicita imperiosamente a consciência ocupá-lo com um conteúdo novo. Todas as iniciativas da consciência refluem, em última instância, para a auto-afirmação (Selbstbehauptung) como ponto fulcral do edifício simbólico da modernidade." VAZ, H. 2002: 26-27

${ }^{8}$ Tradução de minha responsabilidade. Originais em anexo.

${ }^{9}$ Contudo, não seguimos o mesmo caminho trilhado pela autora. Para Sontag, os sentidos atribuídos à tuberculose e ao câncer relacionam-se à paixão. Enquanto a tuberculose foi vista como uma doença dos românticos e apaixonados, o câncer é caracterizado por sua ausência (os pacientes são encarados como sexualmente reprimidos, incapazes de expressar ira). Muitos acreditam que ambas são uma sequela da frustração: o amor dos tuberculosos (mitologicamente encarados como pessoas explosivas ou sentimentais) não é correspondido, e o amor (e outros sentimentos) das pessoas com câncer seria uma força constantemente reprimida. Sontag, finalmente, mostra-se interessada em argumentar a respeito de que, ao contrário das camadas de significação que aderem às doenças como câncer e TB concebendo-as como fatais, a linguagem a respeito das enfermidades deveria desviar-se do conteúdo moral que a cerca. Para nós, trata-se mais de evidenciar a relação entre doença e morte como experiência propulsora de um estado específico da consciência que leva à autorreflexão subjetiva.

\section{REFERÊNCIAS}

AMSTER, Ellen. "The Harem Revealed" and the Islamic-French Family: AlinedeLens and a French Woman's... French Historical Studies, 04/2009, Volume 32, Número

ARFUCH, Leonor. O espaço biográfico: dilemas da subjetividade contemporânea. Trad. Paloma Vidal. Rio de Janeiro: EdUERJ, 2010.

BEAUJOUR, Michel. Miroirs d'encre. Paris: Seuil, 1980.

BLANCHOT, Maurice. O diário íntimo e a narrativa. In: __. O livro por vir. Trad. Leyla Perrone-Moisés. São Paulo: Martins Fontes, 2005. p. 270-278. 
BOLOGNE, Jean Claude Histoire du mariage en Occident, Paris, Hachette, coll. « Pluriel », 1997

BOUTANG, Pierre. Karin Pozzi et la quête de l'immortalité, Paris, La Différence, « Mobile matière », 1991

CANETTI, Elias. A consciência das palavras: ensaios. São Paulo: Companhia das letras, 2011.

COSTA, C. da. (2010) The Diva and Doctor God: Letters from Sarah Bernhardt to Doctor Samuel Pozzi. Xlibris Corporation. Paperback, 2010

DE LENS, A. Journal: 1902-1924 “ L'amour, Je le supplie de m'epargner...”. Paris: La cause des livres, 2007.

FELMAN, S. What Does a Woman Want? Reading and Sexual Difference, Johns Hopkins University Press, 1993

FOUCAULT, M. A hermenêutica do sujeito: curso dado no Collège de France (1981-1982). São Paulo: Editora WMF Martins Fontes, 2010

GHIATI, Claude « Le Maroc des voyageuses françaises au temps du Protectorat. Une vision (de) colonisatrices ? », Genre \& Histoire [En ligne], 8 | Printemps 2011, mis en ligne le 28 octobre 2011, consulté le 17 janvier 2017. URL : http:// genrehistoire.revues.org/1135

HALliWell, S.: The Aesthetics of mimesis. Ancients texts and modern problems, Princeton e Oxford, Princeton University Press, 2002

GOMES, Ângela de Castro. Escrita de si, escrita da História: a título de prólogo. In: GOMES, Ângela de Castro. (Org.) Escrita de si, escrita da história. Rio de Janeiro: FGV, 2004.

LEJEUNE, P. Le Moi des demoiselles: enquête sur le journal de jeune fille. Éditions du Seuil, 1993

MOI, T. From Femininity to Finitude: Freud, Lacan, and Feminism, Again iN: Signs, Vol. 29, No. 3 (Spring 2004), pp. 841-878

POZZI, Journal : 1913-1934, éd. et annot. Claire Paulhan, préf. Lawrence Joseph. Paris: Phébus (édition augmentée), 2005.

RICOEUR, P.Vivant jusqu'a La mort - suivi de Fragments . Paris : Ed. du Seuil,2007

SARLO, B. Tempo passado: cultura da memória e guinada subjetiva. São. Paulo: Companhia das Letras, 2007.

SIMMEL, G. Filosofia do amor. São Paulo: Martins Fontes, 1993.

SONTAG, S. Illness as metaphor. New York: Farrar, Straus an Giroux, 1978. 
VAZ, Henrique Cláudio de Lima. Escritos de Filosofia VII: Raízes da Modernidade, São Paulo: Loyola, 2002.

\section{ANEXO}

"Paris, Samedi soir, 22 novembre 13.

L'autre matin à la Bibliothèque national, comme je retournais déposer une pile de sagesse orientale et les Abhandlungen der Konig [lichen] Gesellschaft der Wissen [schaften], au médaillé hargneux dont l'humeur a resisté à l'écoulement éternel des choses, et qu'au bout d'um na et demi je revois avec le pli hostile de ses lèvres dont problament pas une cellulle n'a changé - ô douceur de na Bibliothèque où les bananes à Buvette n'ont pas même eu temps de mûrir-, je crise Daniel Halévy en veste de peintre, mi-ouvrier sous le velours à cotês, pensif et doux. Lui dire bonjour, s'interroger sur que nous fasions - lui prepare une étude sur Maurras et relit ses articles du temps de l'Affaire [Dreyfus] - moi, combien plus intellectuelle! - et passer. Je luis avais demandé de me prêter sa brochure "Apologie pour notre Passé introuvable, sans penser que c'était indiscrete ni qu 'il oublierait d'alleurs. Et je reçois la brochure, que on lira dans cent ans encore, tant ele tient de sincerité inteligente et de courage moral dans l'histoire de la plus lúgubre des aventures politiques.

Je suis d'une inquiétude incompréhensible, not account for. Une soif: une mauvaise soif me tient; depuis trois semaines, je me joue l'histoire - imaginant de doux épisodes, les yeux clos la nouit dans le noir, cette heure qui est entre aujourdhui et demain -, histoire mediocre, et complètement innocent de ces coupables débauches pensées. Je ne sais pas quel appétit du coeur étrange me tient et me tenaille. Lui ou um autre, n'importe quel...Hélas! que me veut ce sexe avillissant, et à quels airs aspirent ces nerfs, violons à romances?

Honnête, j'ai tâche de travailler. Donc, Nationale où Daniel Halévy, si libéré qu'il soit, m'est pretexte à rever sans que j ele veuille. Mais je n'ai pas la force phisique: deux matins de textes hindus, et j'eus l'air d'avoir été enterrée vivante. Je me raccroche à Fritz Kiener. Celui-là, c'est um cadeau du Hasard, du cher Hasard. Il tient infinitement à moi, et malgré as laideur, j'ai revê, - encore! - que je me jetais dans ses bras em pleurant. Ça, j'aurais bien pu le faire. Ô Fritz, mon ami Fritz, compréhensif, ironiste, germanique bonté, comme je serrarais bien sur votre coeur, si vous saviez!Sur um coeur, sur n'importe quel coeur.. Vous feriez bien le Voyage se un démon vous montrair ces lignes? 
Idiote, Femelle, utérus et médiocrité. (Pozzi, 2005: 57-58)

Versailles, !8 mai 1905

Il fait chaud, je suis paresseuse et je gaspille ma journée, cela n'arrive pas solvente. Je mm'ennuie. Mon dessin ne marche pas, depuis quelque temps rien ne va. Au reste je n'ai pas besoin de m'em étonner, c'est toujours comme cela pous moi à partir du mois d'avril; une espéce de fatigue chronique produit par le travail de l'année. J ele sais bien et cependant j'ai des découragement à pleurer devant mês dessins. Je veux me forcer, je me donne encore plus de mal si c'est possible et je sens três bien que cela ne sert à rien, et même que c'est mauvais. Alors une lettre, lire um bout de jornal, traîner d'une pièce dans une autre? Mais, c 'est du temps perdu, du temps qui ne se retrouvera plus, et puis cela m'ennuie horriblement.

La semaine dernière nous sommes allées à l'Opéra, Marguerite et moi, avec les Diérterle, voir Tristan et Iseult, c'est merveilleux, surtout le dernier acte, celui de la mort d'Iseult et de Tristan. On songe au roman de Wagner et de Mme Wesendonck qu'il a coulu synthétiser dans son ópera. La vérité fut encore plus triste. Ils ne mourerurent mais il oublia. C'est Van Dyck qui incarnait le rôle de Tristan, il a fort bien interprété et as voix, encore qu'un peu faible par moments pour cette musique si dure aux chanteurs, et toujours três belle; mais son physique est par trop disgracieux, et peut-on se figurer um Tristan petit et obèse avec une grosse tête un peu poupine encadrée de barbe rousse? Mlle Grandjean était assez bonne dans Iseult mais ne m'a pas embalée.

Dimanche, je suis retournée au Salon [ des artistes] avec Marguerite. J'ai revu des salles déjà visités, les merveilleux tableux de Sorolla J. Bastida, d'une allure si vivante, avec une largeur de touches, une intensité de lumière tellement éttonantes! La Grève de Venise par Mlle Rondenay a um succès três mérité, c'est três humain, três senti et il y a surtou tau premier plan des miséreux vraiment tragiques mais l'ensemble du tableau me semble un peu grand, un peu vide pour la composition, et il y a à gauche une grande muraille nue qui n'est guère interessante. Elle est bien heureuse de pouvoir déjà une telle oeuvre. Il y a à peine six ans qu'elle est entrée à la École, je crois. J'aime beaucoup Les Morphinomanes de Matignon, où s'hypnosent et se renversent sur des divans à la lueur d'une lampe de femmes d'une beuté étrang et maladive. C'est um coloris ravissant et bizarre comme le sujet et on pense tout de suíte au poème de Baudelaire.

De Chabas, il y a une délicieuse petite ondine aux yeux et aux cheveuc pâles qui se baigne dans um étang sous une rayon de lune. Ce corps d'enfant aux formes frêles et pures et charmant et l'ensemble est d'une harmonie três distinguée. Et 
puis, il y a aussi Les jeunes filles de l'ilê de Marken du bon Bail, d'um três joli sentiment. Le charge fougueuse des cuirassieres de Detaille, À la porsuite de la Gloire et puis... et puis on est tellement fatigue que'on songe plus qu'à s'aller. ( De Lens, 2007: 47-49)

Fez, 29 mai 1920

Autrefois, j'ai cru être independante et forte; j'ai eu la volonté de fair ema vie toute seule, par moi-même. Les années em passant m'ont appris ma faiblesse et que j'avais tant besoin de lui. Un besoin si intense qu'il m'est devenu une torture. Il est inutile d'écrire mês pensées aujourd-hui; elles se pressent dans ma téte malgré moi et me tournement. Retour à cet état nerveux qui me fit tant souffrir il y a déjà longtemps, dont j'avais cru ne jamais sortir et qui s'apaisa dans le plus grand benhuer de mon existence. Ce bonheur-là existe toujour, intact, plus parfait encore d'avoir duré, plus assuré de lui-même. C'est à lui que je m'accroche, que je demande le secours.

L'obtiendrai-je? Sera-i-il plus fort que le déséquilibre de mon cerveau? Ne plus penser, ne plus raisonner, vivre bêtement, sans soucis, comme si on devait toujours vivre, être une simples brute: ce raffinement intellectuel que la civilisation met em nous et que l'homme célébre avec orgueil, c'est l'instrument même de la souffrance (De Lens, A. 284).

\section{0 juin [1931] à Vence}

Tout le moi de mai três misérable. Docteur Labonnette: "Vous avez des crises d'épilepsie du nerf pneumogastrique... Ce n'est pas précisemente de l'asthme... C'est um nerveux respiratoire Anaphylaxie"

Ver la Pentecoste, le temps devient enfin beau, et la fièvre a diminué.

On m'a emportée le 29 mai ici. Emportée, portée. Ici, je croyais guérir immédiatement comme em 1925, aprés le martyre des dix moi bras-asthme. Mais alors, j'Étais entiére, je ne m'étais pas abandonnée. Et alors, je prenais de la morphine tous le jours, ce qui tout de même permet que la machine ait diz heures de repôs. A présent, c'est um chiffon, um voile de âme flottant autour de moi comme um chiffon. Et, à présent, je n'ai plus la morphine. Si, aujourd-hui, et si peu. Tout de même, c'est grâce à ce peu que j'écris.

Hier, j'ai envisagé la mort. Voilá un mot que ces cahiers connaissent" Oui, mais ils n'y croyaient pas.

Le Héros-est-un-simulateur-ou-un-imbecile est encore venu sous mês fenêtres huit jours avant le départ ( le samedi veille du dimanche de Pentecôte). Qui le 
croirait? Ah, même pas Rose de l'Acadêmie. Partons, qu'importe. Celle qui part ne laisse rien, que tout son passé. Ô Souffle, souffle, refuse le passé! 58 respirations par minute, docteur... (Pozzi, c. 2005. p .617)

Recebido: 29/11/2017

Aceito: 07/06/2018 